\title{
Purchasing Patterns and Consumer Level Waste of Fruits and Vegetables in Urban and Peri-Urban Centers in the Philippines
}

\author{
Elda B. Esguerra1, Dormita R. del Carmen1', Rosa S. Rolle ${ }^{2}$ \\ ${ }^{1}$ Postharvest Horticulture Training and Research Center, College of Agriculture and Food Science, University of the Philippines \\ Los Banos, Laguna, Philippines \\ ${ }^{2}$ Food and Agriculture Organization of the United Nations, Rome, Italy \\ Email: ebesguerra@up.edu.ph
}

How to cite this paper: Esguerra, E.B., del Carmen, D.R. and Rolle, R.S. (2017) Purchasing Patterns and Consumer Level Waste of Fruits and Vegetables in Urban and Peri-Urban Centers in the Philippines. Food and Nutrition Sciences, 8, 961-977. https://doi.org/10.4236/fns.2017.810069

Received: July 28, 2017

Accepted: October 24, 2017

Published: October 27, 2017

Copyright (c) 2017 by authors and Scientific Research Publishing Inc. This work is licensed under the Creative Commons Attribution International License (CC BY 4.0).

http://creativecommons.org/licenses/by/4.0/

(c) (i) Open Access

\begin{abstract}
Fruits and vegetables are inherently perishable hence they are considered as one of the most wasted categories of food. While several studies have been conducted to assess consumer level waste of fruits and vegetables, few have been conducted in developing countries like the Philippines. A survey, using a pre-tested questionnaire, and involving 500 respondents, was conducted in selected urban and peri-urban areas in the Philippines, to ascertain consumer level fruit and vegetable waste. The quantities of fruits and vegetables wasted by supermarket shoppers and those who purchased fruits in wet markets were comparably low at 3\% - 4\%. This low level of consumer fruit and vegetable waste was attributed to the small quantities (250 to 500 grams per purchase) purchased by consumers in both categories of markets. Consumer level fruit and vegetable waste, showed a positive correlation to household size. The level of fruit waste was positively related to household income, and negatively related to shopper's age. Consumers who shopped in supermarkets, purchased larger quantities of fruit when compared to those who shopped in wet markets. Wet market shoppers on the other hand, purchased large quantities of vegetables. Decay, and quality loss manifested by shriveling, wilting, toughening, browning and softening were the main characteristics of fruits and vegetables discarded by consumers. The underlying causes of this waste, cited by respondents included "forgot to eat", "poor quality", "forgot to cook" and "overbuying". Consumer efforts to minimize waste include buying enough for consumption, consuming or using immediately after purchase, planning their menus, improving storage and purchasing produce that is of good quality.
\end{abstract}

\section{Keywords}

Fruit and Vegetable Waste, Supermarket, Wet Market 


\section{Introduction}

Food loss and waste occur at all stages in the food supply chain from harvesting, through post-harvest handling, processing, distribution and finally consumption. It has been estimated that in developing countries $40 \%$ of losses occur at postharvest and processing levels, while in industrialized countries more than $40 \%$ of losses take place at the retail and consumer levels [1]. Food losses occurring at the end of the food chain (retail and final consumption) are referred to as "food waste" [2] [3]. Parfit et al. (2010) indicated that the most wasted food items are those that are highly perishable typified by fresh fruits and vegetables [4] [5]. The causes of household level food waste among others include a) spoilage of food before and after preparation, b) rodent and insect infestation, and c) those caused by decay-causing organisms [6]. Non-technical factors affecting consumer waste include seasonality of produce, gender, household size and income among others. According to Muth et al. (2007), females waste more than males, and the higher the household income and size, the higher the level of food waste [6]. Other studies showed that adults waste more than children; households with children tend to waste more than without children, and, that young people waste more than older people [3].

Increasing urbanization accompanied by increasing incomes, the changing tastes and lifestyles of consumers, more women in the workforce and the need for convenience have resulted in the changes in consumer buying habits. The growth of supermarkets and hypermarkets in Asia [7] has also contributed to changes in buying habits. These modern retail outlets offer a variety of food items and convenience to shoppers hence their increasing patronage. Digal and Concepcion (2004) showed that in the Philippines, $15 \%$ of vegetables are sold through supermarkets in Metro Manila [7]. Romo et al. (2009) reported that modern food retail has reached $45 \%$ of urban food retail and is rapidly transforming with increasing fresh produce sales [8]. Despite supermarket growth, traditional wet markets still enjoy high patronage when it comes to fresh produce due to the perception that fruits and vegetables are fresher in wet markets than in supermarkets. The change in the buying habits of consumers may have an effect on the wastage of food items particularly fresh fruits and vegetables.

In developed countries, studies on food waste at the consumer level have resulted in the identification of holistic definitive programs or actions to address food waste reduction. These programs complete the picture of the extent of losses along the supply chain from farm to table. In developing countries as is the case of the Philippines, studies have focused on post-harvest losses, with no study to date on consumer level waste. The purpose of the current study was to gain some perspective as to the extent of wastage of fruits and vegetables at the consumer level and to determine the factors that influence the levels of these wastes.

\section{Methodology}

To achieve the objectives of this research, a survey on fruit and vegetable waste 
at the household level was conducted in selected urban and peri-urban areas in the Philippines. Using pre-tested questionnaires, the survey was administered through face to face interviews of market shoppers and through the distribution of pre-tested questionnaires to households. The respondents included shoppers from the three (3) supermarkets, three (3) wet markets, private and government offices, schools, and residential estates in cities of Metro Manila (representing the National Capital Region) and in CALABARZON (Cavite, Laguna, Batangas, Rizal and Quezon) which represent the outlying peri-urban provinces of Metro Manila (Figure 1). CALABARZON was included due to its rapid rate of urbanization and expansion of industrial estates, exclusive schools, residential areas, supermarkets and hypermarkets.

The questionnaire addressed two issues, namely: 1) socio-demographic characteristics of consumers, and 2) consumer purchase behavior: types and volume of fruits, vegetables including fresh-cuts purchased, storage practices, nature and extent of wastes and measures taken to minimize the levels of waste. Observations were also made on the following: most frequently purchased fruits and vegetables in the whole and fresh-cut forms; purchase preferences (e.g. for fruits and vegetables that are pre-packed or sold in the loose format), and for the purchase of fresh cuts or ready-to-eat and/or cook fruits and vegetables, and those items sold on discount.

A total of 600 questionnaires were retrieved; each one was checked for completeness of information. Equal numbers (250 each) of survey questionnaires retrieved from the supermarket and wet market shoppers were then selected. The study employed qualitative and quantitative analyses. Data were presented in

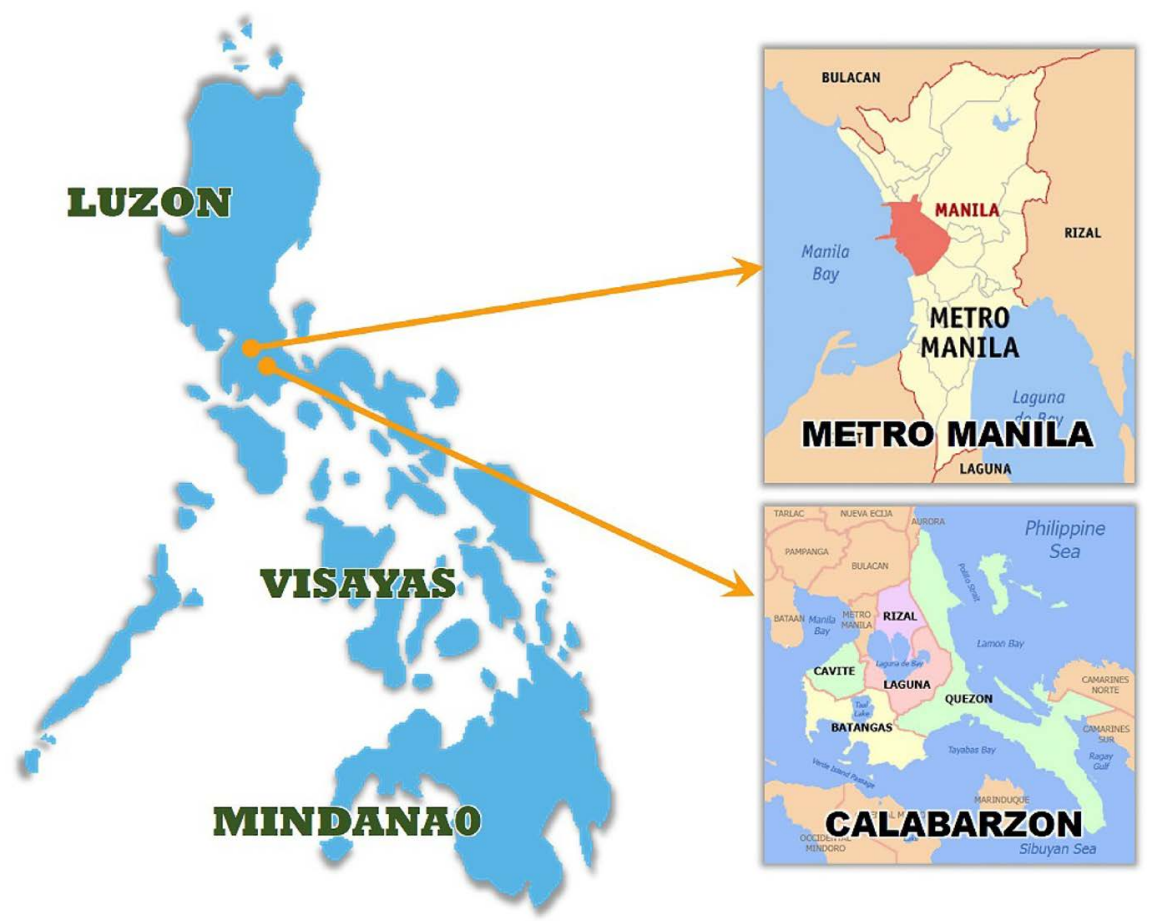

Figure 1. Map of the Philippines indicating the place of residence of respondents. 
tabular and graphical forms using descriptive statistics such as frequency counts, percentages, and means. Comparison and/or differences between the two groups of respondents in terms of socio-demographic characteristics, purchase behavior and practices, and levels of losses were determined using Chi-square, t-tests, and Analysis of Variance (ANOVA). Correlation analysis was also used to determine the factors associated with fruit and vegetable purchases and wastes.

\section{Results and Discussion}

\section{Characteristics of Consumer Respondents}

The socio demographic profile of respondents or consumers shopping in wet markets and in supermarkets is shown in Table 1. A majority of the respondents interviewed in both markets originated from the CALABARZON area. The large number of respondents in CALABARZON supermarkets indicates the expansion of retail operations in the provincial peri-urban areas to widen the consumer base [9]. The report further indicated that with this expansion, consumer preference for shopping in traditional wet markets would likely decline. However, based on the results of Chi-square test $\left(X^{2}=0.179\right)$, there was no significant difference in the percentage of respondents from each area, shopping in either supermarkets or wet markets.

A majority of the respondents shopping in both types of markets were females, aged 20 to 30 years old (Table 1). The percentage of shoppers in the age ranges of $31-40$ and 41 - 50 in both market types were almost the same. Differences between age groups were not significant $\left(X^{2}=0.95\right)$. In both market types, a majority of the respondents were mothers or housewives ( $46 \%$ in wet market and $44.6 \%$ in supermarket). This was closely followed by the son or daughter shopping in wet markets (36.7\%) or in supermarkets (39.4\%). This supports the observation wherein a majority of the shoppers in both market types are in the age range of 20 - 30 years old. Few husbands/fathers engage in fruit and vegetable procurement.

Consumers who shopped in both categories of markets, originated from households composed of the husband, wife, children and other adults living with them-mostly the grandparents which is typical of the Filipino family. The composition of the household did not have any influence on the choice of markets to $\operatorname{shop}\left(X^{2}=0.307\right)$.

Household income significantly influenced the choice of shopping locale. Higher income shoppers generally shopped in supermarkets. A majority of low income shoppers still preferred shopping in traditional wet markets for food, although, according to survey results a growing percentage of low income consumers shopped in supermarkets (income levels of PhP 100,000 - 200,000 which represent the $\mathrm{D}$ class). These changing buying habits align with the expansion of modern retail markets in the provinces. Moreover, this also brings in a new perspective, that supermarkets are no longer the shopping venue of higher income consumers. 
Table 1. Socio-demographic characteristics of respondents classified/grouped based on their major source of fruits and vegetables.

\begin{tabular}{|c|c|c|}
\hline \multirow{2}{*}{ CHARACTERISTICS OF RESPONDENTS } & \multirow{2}{*}{$\begin{array}{c}\text { Wet Market Shoppers } \\
\qquad(\mathrm{n}=250)\end{array}$} & \multirow{2}{*}{$\begin{array}{c}\text { Supermarket Shoppers } \\
\qquad(\mathrm{n}=250)\end{array}$} \\
\hline & & \\
\hline \multicolumn{3}{|l|}{ Place of Residencel Origin } \\
\hline Metro Manila & 34.8 & 28.8 \\
\hline CALABARZON area & 65.2 & 71.2 \\
\hline \multicolumn{3}{|l|}{$X^{2}=0.179 \mathrm{~ns}$} \\
\hline \multicolumn{3}{|l|}{ Gender } \\
\hline Male & 24.6 & 30.4 \\
\hline Female & 75.4 & 69.6 \\
\hline \multicolumn{3}{|l|}{$X^{2}=0.169 \mathrm{~ns}$} \\
\hline \multicolumn{3}{|l|}{ Age Range } \\
\hline $20-30$ & 40.5 & 41.5 \\
\hline $31-40$ & 24.2 & 25.6 \\
\hline $41-50$ & 21.3 & 19.1 \\
\hline $51-60$ & 11.1 & 11.8 \\
\hline Above 60 & 2.9 & 2.0 \\
\hline \multicolumn{3}{|l|}{$X^{2}=0.95 \mathrm{~ns}$} \\
\hline \multicolumn{3}{|l|}{ Position in the Family } \\
\hline Mother/wife & 46.0 & 44.6 \\
\hline Father/ Husband & 12.5 & 11.6 \\
\hline Daughter/Son & 36.7 & 39.4 \\
\hline Grandparent & 1.6 & 0.8 \\
\hline Others & 3.2 & 3.6 \\
\hline \multicolumn{3}{|l|}{$X^{2}=0.96 \mathrm{~ns}$} \\
\hline Average Household Size & 5.0 & 4.6 \\
\hline \multicolumn{3}{|l|}{$\mathrm{F}=0.014^{* *}$} \\
\hline \multicolumn{3}{|l|}{ Household Composition } \\
\hline Single household & 5.4 & 10.0 \\
\hline Husband and wife only & 5.8 & 5.0 \\
\hline Husband \& wife +other adults & 2.9 & 3.7 \\
\hline Husband \& wife + children + adults & 69.2 & 68.4 \\
\hline Others & 16.7 & 12.9 \\
\hline \multicolumn{3}{|l|}{$X^{2}=0.307 \mathrm{~ns}$} \\
\hline \multicolumn{3}{|l|}{ Household Income (Range) } \\
\hline Below $100 \mathrm{~K}$ & 26.1 & 17.4 \\
\hline $100-200 \mathrm{~K}$ & 27.0 & 26.0 \\
\hline $201-300 \mathrm{~K}$ & 19.5 & 17.4 \\
\hline $301-500 \mathrm{k}$ & 14.2 & 21.3 \\
\hline Above 501 & 13.3 & 17.9 \\
\hline$X^{2}=0.048^{*}$ & & \\
\hline
\end{tabular}

NS: not significant at $5 \%$ level; ${ }^{*}$ significant at $5 \%$ level; ${ }^{* *}$ significant at $1 \%$ level. 


\section{Consumer Purchasing Practices}

Quantities of Fruits and Vegetables Purchased in Different Categories of Markets on a Weekly Basis

On a weekly basis, shoppers purchase between 4.9 to 5.6 grams of fruits and about 4.3 to 4.8 grams of vegetables (Table 2). Respondents who purchased fruits in supermarkets, purchased larger quantities than those who purchased their fruits in wet markets. Wet market shoppers purchased comparably larger quantities of vegetables than did supermarket buyers. Differences were also observed with regard to the types of fruits purchased (Figure 2). Bananas were purchased in the largest quantity by both categories of shoppers. The second most popularly purchased fruits were watermelons and pineapples, wherein the quantities purchased by supermarket shoppers was greater than that procured by wet market buyers. Apples and oranges were the most popularly purchased temperate and imported fruits by both groups of buyers. The other fruits purchased, included calamondin, grapes, papaya, avocado, rambutan, and lanzones.

Consumers also purchased different quantities of the different types of vegetables (Figure 3). Tropical vegetables including tomatoes, eggplants and potatoes were the topmost vegetables purchased by wet market shoppers, while potatoes, onions and tomatoes were purchased by supermarket shoppers. These vegetables are basic ingredients in most Filipino dishes. Other vegetables purchased include lettuce, kangkong, mustard, snap beans and bell pepper. Vegetables were purchased in comparably smaller quantities than fruits, indicating that

Table 2. Total quantity of fruits and vegetables purchased on a weekly basis by respondent group.

\begin{tabular}{ccc}
\hline Produce & \multicolumn{2}{c}{ Quantity Bought (grams)/Shoppers Group } \\
\hline Type & Wet Market & Supermarket \\
\hline Fruits (in grams) & 4864 & 5585 \\
$(F=5.286)$ & & 4258 \\
Vegetable (in grams) & 4839 & \\
$(F=5.350)$ & & \\
\hline
\end{tabular}

${ }^{*}$ Differences between two groups of shoppers are significant at $5 \%$ level.

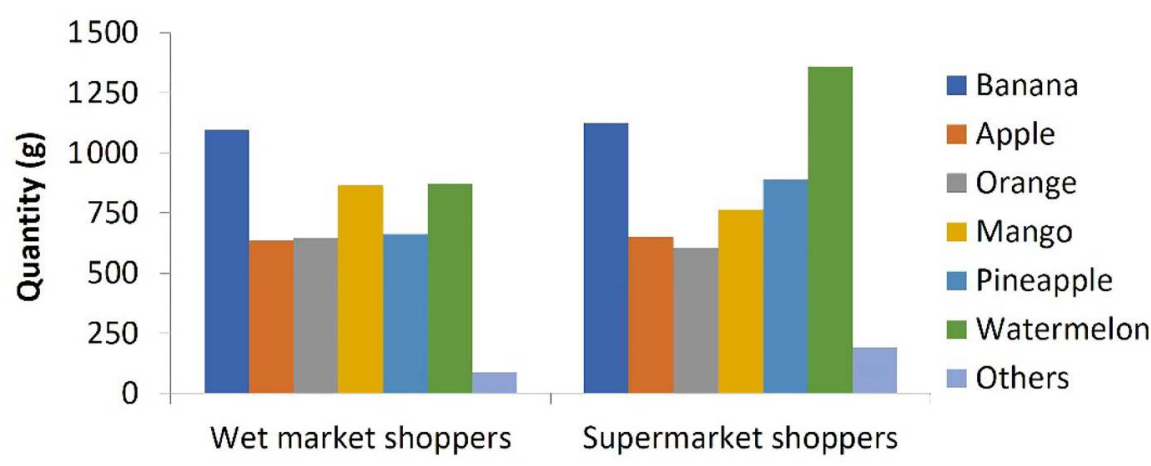

Figure 2. Average quantities of different types of fruits purchased on a weekly basis by respondent group. 


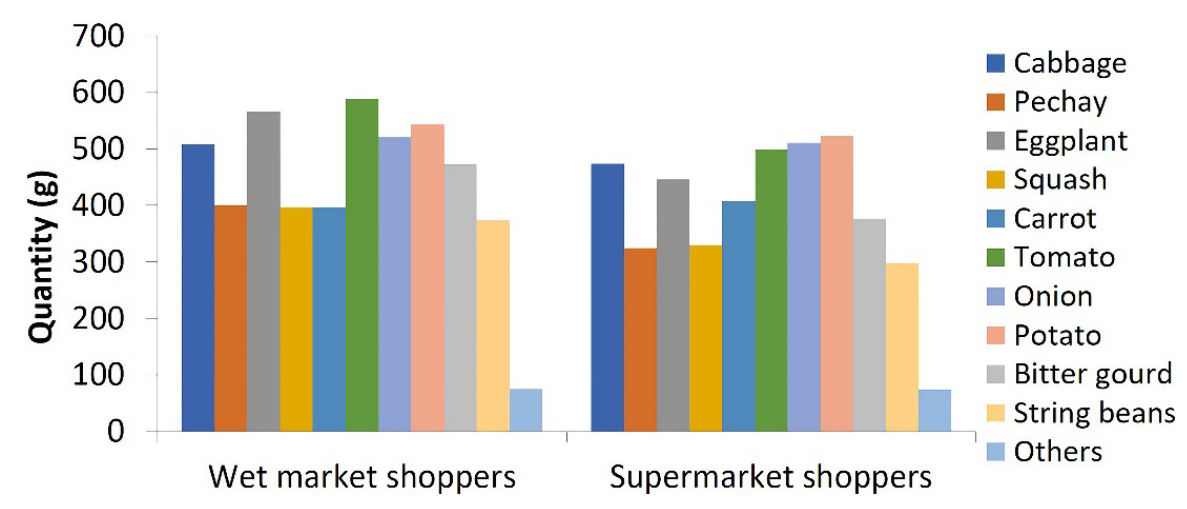

Figure 3. Average quantities of different types of vegetables purchased on a weekly basis by respondent group.

vegetable consumption in the country is relatively low.

Quantities of Fruit and Vegetable Purchased Per-Capita

Supermarket shoppers purchased larger quantities of fruits (179 grams) on a per capita basis, than did wet market shoppers (139 grams). With regards to vegetables, little difference was observed between the two respondent groups (132 - 138 grams). When compared to the 2003 data from the Food and Nutrition Research Institute (FNRI) of the Philippines where the average daily consumption per person was 110 grams of vegetables and 54 grams for fruits [10], these purchases by urban households (which could equate to consumption) showed a marked increase particularly in fruit purchases. The total quantity of fruits and vegetables purchased or consumed which ranged from 277 to 305 grams was actually not too far to the World Health Organization's (WHO) recommended daily per capita intake of 400 grams of vegetables and fruits. This could be attributed to the growing level of health consciousness of the Filipino population.

Reasons for Buying Fruits and Vegetables in Wet Markets vs. Supermarkets

Both groups differed as to their rationale for purchasing fruits and vegetables in different locations. Shoppers purchased fruits and vegetables in wet markets, owing to lower price, while those who shopped in supermarkets reported convenience as their priority (Figure 4). Accessibility was the second common reason for the point of purchase. Furthermore, wet markets were often preferred for the availability of traditional fruits and vegetables, while supermarket shoppers were interested in the variety of options available. The convenience offered by supermarkets in terms of variety of food items-fresh fruits and vegetables both imported and locally produced, intact or as fresh-cuts-was preferred particularly by working women and young urban professionals who have less time to prepare food.

A high percentage (34\%) of supermarket buyers paid attention also to neat packaging as against only $3 \%$ for wet market buyers. Retail packaging is increasingly accepted and patronized by consumers. A study of Aban et al. (2009) on consumer perceptions of food safety indicated that consumers defined food safety as "proper food handling" and some have started to be food safety 


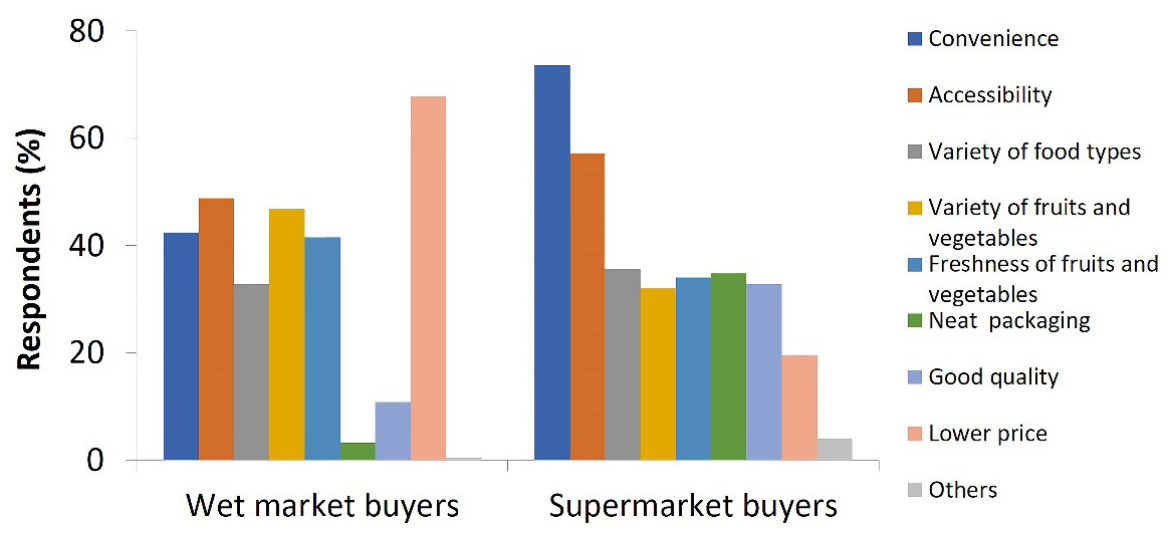

Figure 4. Reasons for buying fruits and vegetables in wet markets vs. supermarkets.

conscious by buying vegetables that are well-packaged [11]. It appeared therefore that neat packaging is associated with food safety since cross-contamination is prevented as against vegetables sold in loose formats in wet markets.

In the case of wet market buyers, lower price was the main determinant of patronage among $67 \%$ of the respondents. Also, in wet markets where fresh fruits and vegetables are sold in a loose format, consumers can opt to purchase only very small quantities of produce-such as 2 - 3 pieces of garlic, onions or potatoes - unlike in supermarkets where most produce is pre-packaged.

Formats of Fruits and Vegetables Purchased

A majority of respondents from both groups reported that they preferred buying fruits and vegetables in their intact or whole form. The difference between the two groups of buyers was not significant. A very low percentage of respondents from both the wet and supermarket groups purchased fresh cuts although fresh cuts appeared to be regularly purchased by supermarket shoppers. Fruits and vegetables in the loose format were selected by buyers before weighing and purchasing. Buyers in both wet markets and supermarkets showed a preference for purchasing fruits in the loose format. Retail-packaged produce was more likely to be purchased by supermarket shoppers than by wet market shoppers.

Almost all fruits and vegetables were sold in the loose format in wet markets, providing consumers with a fairly high level of flexibility in purchasing quantities needed. This allowed consumers to choose the number of purchases at any one time. In supermarkets, a higher percentage of consumers purchased prepackaged fruits and vegetables than those buying in wet markets since they perceived the produce to be safe and of good quality. On the other hand, buyers in wet markets perceived packaged produce be of poor quality, and few purchased pre-packaged fruits and vegetables.

Frequency of Buying

There was a highly significant difference $\left(X^{2}=0\right)$ between shoppers in wet markets $v s$ in supermarkets when it comes to frequency of buying. A higher percentage (14.8\%) of wet market shoppers shopped on a daily basis when compared to only $6.1 \%$ of the respondents who shopped in supermarkets (Figure 5). 
This may be due in part to the prevalence of small wet markets in the barangays in the form of mobile small retailers and hawkers or the "mom and pop" stores that sell perishable produce [8]. Moreover, a larger number of wet market shoppers shop twice weekly, owing largely to the low buying power of the household which for any given period is just enough to purchase food for the next three (3) days. The percentage of respondents shopping once a week in wet markets was only slightly higher than that of those purchasing twice weekly.

Approximately $57 \%$ of supermarket shoppers, shopped once weekly, only $23.4 \%$ shopped twice weekly and a very low percentage shopped on a daily basis (Figure 5). It should be noted that working women were the main shoppers.

\section{Storage of Fruits and Vegetables Purchased in the Household}

Both respondent groups stored their fruit and vegetable purchases in the refrigerator, indicating awareness on the effect of low temperature in maintaining quality and extending shelf life. Both respondent groups stored fresh produce either packaged in plastic or in the loose format in the refrigerator (Figure 6).

Depending on the commodity, packaging in plastic bags is advantageous in preventing moisture loss from the stored produce. In some cases, as is the case for leafy vegetables, packaging in plastic bags can accelerate the rate of decay which is often the case for leafy vegetables.

Fruits were also commonly kept in the loose format in the kitchen or in fruit bowl for consumption as dessert. Onions and potatoes were frequently stored in a kitchen bowl, given their low level of perishability.

Consumer Level-Waste of Fruits and Vegetables

Estimated Levels of Waste by Respondent Group

Respondents were asked to rate, based on their opinion or provide an estimate

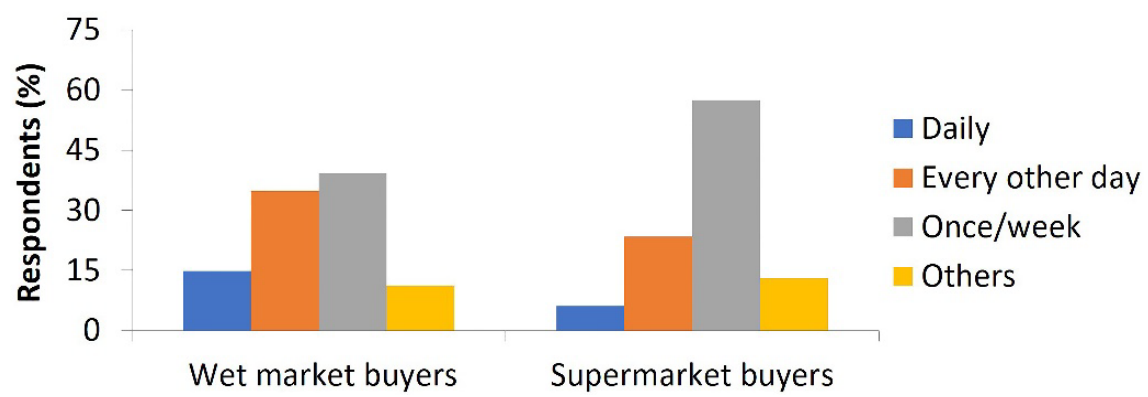

Figure 5. Frequency of purchasing fruits and vegetables by respondent group.

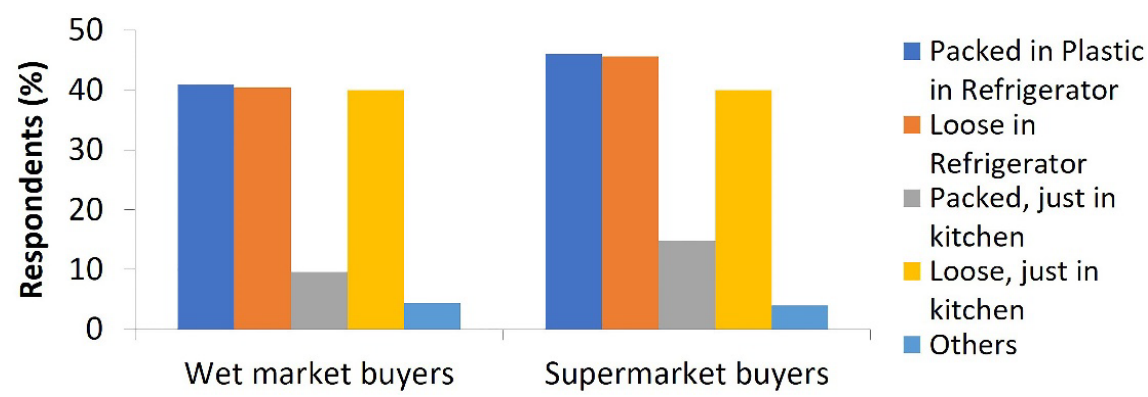

Figure 6. Storage of fruits and vegetables at the household level. 
Table 3. Consumer level fruit and vegetable waste (\% in range scale) by respondent group.

\begin{tabular}{ccccc}
\hline \multirow{2}{*}{$\begin{array}{c}\text { Range } \\
\text { Scale }\end{array}$} & \multicolumn{3}{c}{ Percent Reporting/Produce Type/Market Type } \\
\cline { 2 - 5 } & Fruits & \multicolumn{3}{c}{ Vegetables } \\
\cline { 2 - 5 } & Wet Market & Supermarket & Wet Market & Supermarket \\
\hline Less than 5\% & 86.4 & 79.5 & 89.0 & 81.6 \\
$5 \%-10 \%$ & 11.8 & 20.0 & 8.6 & 15.6 \\
$11 \%-20 \%$ & 3.6 & 4.0 & 2.3 & 2.3 \\
More than 20\% & 1.4 & 1.3 & 0 & 0.7 \\
\hline
\end{tabular}

based on their experience, the waste in the fruits and vegetables that they bought. Both respondent groups reported that the quantities of fruits and vegetables wasted by them were minimal (Table 3 ) indicating that consumers in both market types were not generally wasteful. Eighty-six per cent (86\%) of wet market fruit shoppers and $89 \%$ of wet market vegetable shoppers, informed that they waste less than $5 \%$ of their fruit and vegetable purchases. In the case of supermarket shoppers, a lower percentage, (79\% for fruits and $82 \%$ for vegetables) reported incurring less than $5 \%$ waste. It should, however, be noted that the number of supermarket buyers incurring between $5 \%-10 \%$ waste was comparably higher.

Calculated Quantities of Consumer Level Waste of Selected Fruits and Vegetables Purchased by Respondent Groups

Based on the average quantities of fruits and vegetables purchased on a weekly basis and the reported range scale of waste, the actual quantities of fruits and vegetables wasted following their purchase was calculated. Wastes were significantly higher for fruits and vegetables purchased by supermarket buyers than by wet market buyers (Table 4). Fruit wastage averaged at 3.2\% for wet market shoppers and 3.9\% for supermarket shoppers. Vegetable waste amounted to $3 \%$ for wet market shoppers and 3.7\% for supermarket shoppers. When compared to data from developed countries, the waste figures obtained in this study are much lower. The low level of waste can be attributed to the small average weekly quantity of each type of fruit and vegetables purchased by respondents in both market types which ranged from 695 to 797 grams for fruits and only 387 to 440 grams for vegetables. It should be noted also that in both market types, consumers still prefer to buy fruits and vegetables in the loose format and hence have greater flexibility in buying only the amount that they require.

Even in supermarkets where a majority of fruits and vegetables are pre-packaged, the quantity purchased was small (usually 250 to 500 grams per pack) which was adequate for households. This was validated when respondents in both market types were asked to rate the adequacy of purchased volume of fruits and vegetables. Both respondent groups answered that the volume they bought was just enough for their consumption. A glean at the shopping bag or cart of the shoppers in wet markets and supermarkets respectively, proved that the quantities 
Table 4. Calculated levels of wastes (\%) in fruits and vegetables commonly bought in wet markets and supermarkets.

\begin{tabular}{|c|c|c|}
\hline \multirow{2}{*}{ Commodity } & \multicolumn{2}{|c|}{ Wastes (\%)/Source } \\
\hline & Wet Market & Supermarket \\
\hline \multicolumn{3}{|l|}{ FRUITS } \\
\hline Banana & 3.72 & 4.40 \\
\hline Apple & 3.18 & 4.00 \\
\hline Orange & 3.30 & 2.74 \\
\hline Mango & 1.84 & 2.50 \\
\hline Pineapple & 4.42 & 4.27 \\
\hline Watermelon & 2.63 & 4.19 \\
\hline Average $\mathrm{F}=8.552^{* *}$ & 3.18 & 3.85 \\
\hline \multicolumn{3}{|l|}{ VEGETABLES } \\
\hline Cabbage & 3.40 & 3.49 \\
\hline Pechay & 3.13 & 3.54 \\
\hline Eggplant & 3.92 & 4.41 \\
\hline Squash & 3.13 & 3.36 \\
\hline Tomato & 3.42 & 4.10 \\
\hline Onion & 2.67 & 3.47 \\
\hline Potato & 2.97 & 3.63 \\
\hline Carrot & 3.27 & 3.68 \\
\hline Bittergourd & 3.30 & 4.31 \\
\hline String beans & 3.32 & 3.64 \\
\hline Average $\mathrm{F}=7.582^{\star *}$ & 3.25 & 3.66 \\
\hline
\end{tabular}

${ }^{*}$ Significant at $1 \%$ level.

purchased, appeared to be just enough hence losses were minimal.

Pineapples and bananas were most wasted by both wet market and supermarket buyers. Decay owing to the inability to consume was the main cause of losses in bananas, while in the case of pineapples, over-ripening and fermentation (often resulting from damage due to puncture,) was the main cause of loss. The lowest level of waste was recorded for mangoes, largely due to the fact that mangoes are one of the highly favored fruits in the Philippines and are consumed on ripening.

The highest level of vegetable waste occurred in eggplants followed by bitter gourds and tomatoes (Table 4). Eggplants and bitter gourds are highly perishable especially when not stored under refrigerated conditions. Bitter gourd assumes a yellow color, while eggplant undergoes rapid softening. Waste in squash was also high since it is sold as a fresh-cut, in quarters or halves. Waste in onions and potatoes was low when compared with other vegetables, given their low level of perishability due to their inherent dormant state after harvest. 


\section{Factors that Contribute to Consumer Level Waste of Fruits and Vegetables}

The inherent perishability of fruits and vegetables was the main cause of consumer level waste. Fruits purchased in wet markets or in supermarkets underwent decay mainly due to rotting (Table 5), softening or over-ripening, while shriveling or wilting owing to water loss were the main cause of wastage for vegetables. Vegetables are also prone to decay which manifested in the form of bacterial soft rot which is common in leafy vegetables as well as in tomatoes and carrots.

Browning is yet another disorder that commonly occurs in fruits such as apples and bananas when stored under low temperature conditions.

\section{Underlying Causes of Consumer Level Fruit and Vegetable Waste}

The main reason given by shoppers for wasting fruits purchased in both wet markets and supermarkets was that they "forgot to eat" the fruit. This was the case for a higher percentage of supermarket shoppers than for wet market shoppers (Table 6). Poor quality was a major cause of waste for wet market shoppers, while over-buying was a major cause for supermarket shoppers. In the case of the latter, this may be attributed to the esthetics of the packaging of the produce, which appeals to consumers, enticing them to purchase more than is required.

Vegetable waste resulted from "forgetting to cook" the produce purchased (Table 6). This is indicative of the lack of meal planning such that the vegetables kept in the chiller section of the refrigerator underwent spoilage due to rotting. Over-buying was yet is another underlying cause of waste in vegetables, indicating the failure of consumers to plan their fruit and vegetable purchases. Poor quality was yet another underlying cause of waste, with a higher percentage of shoppers in wet markets reporting this than those shopping in supermarkets. This also highlights the fact that better quality produce was sold in supermarkets.

Ways of Disposing of Fruit and Vegetable Waste

The most common method of disposing of fruit and vegetable waste, was by using it as animal feed. A higher percentage of those who purchased their fruits and vegetables in supermarkets, disposed of their uneaten produce through garbage disposal (Figure 7). It would appear that those who shopped in supermarkets routinely dispose of uneaten produce. Several also used the wasted fruits

Table 5. Factors that contribute to consumer level fruit waste.

\begin{tabular}{ccccc}
\hline \multirow{2}{*}{ Nature of Waste } & \multicolumn{3}{c}{ Percent Reporting/Produce Type/Market Type } \\
\cline { 2 - 5 } & \multicolumn{2}{c}{ Fruits } & \multicolumn{2}{c}{ Vegetables } \\
\cline { 2 - 5 } & Wet Market & Supermarket & Wet Market & Supermarket \\
\hline Rot/decay & 17.1 & 22.8 & 29.9 & 32.1 \\
Shrivelling/wilting & 2.8 & 3.0 & 6.5 & 10.6 \\
Hardening/toughening & - & - & 3.0 & 3.3 \\
Browning & 8.1 & 10.3 & 5.5 & 5.1 \\
Softening/overripening & 18.5 & 19.3 & 6.1 & 8.0 \\
\hline
\end{tabular}


Table 6. Underlying causes of consumer level waste in fruits and vegetables by respondent group.

\begin{tabular}{|c|c|c|c|c|c|c|c|c|c|c|}
\hline \multirow[b]{2}{*}{ Commodity } & \multicolumn{5}{|c|}{ Wet Market $(n=250)$} & \multicolumn{5}{|c|}{ Supermarket $(n=250)$} \\
\hline & $\begin{array}{c}\text { Forgot } \\
\text { to eat }\end{array}$ & $\begin{array}{c}\text { Poor } \\
\text { quality }\end{array}$ & $\begin{array}{l}\text { Forgot } \\
\text { to cook }\end{array}$ & $\begin{array}{l}\text { Over } \\
\text { bought }\end{array}$ & Others & $\begin{array}{c}\text { Forgot } \\
\text { to eat }\end{array}$ & $\begin{array}{c}\text { Poor } \\
\text { quality }\end{array}$ & $\begin{array}{l}\text { Forgot } \\
\text { to cook }\end{array}$ & $\begin{array}{c}\text { Over } \\
\text { bought }\end{array}$ & Others \\
\hline \multicolumn{11}{|l|}{ Major Fruits } \\
\hline Banana & 48.4 & 10.0 & 2.8 & 10.4 & 0.4 & 53.6 & 9.6 & 2.0 & 15.5 & 3.6 \\
\hline Apple & 36.4 & 8.4 & 0.8 & 3.6 & 0.4 & 41.2 & 5.2 & 0.8 & 8.0 & 2.4 \\
\hline Orange & 26.4 & 10.0 & 1.2 & 2.0 & 2.4 & 32.0 & 5.6 & 1.2 & 57.6 & 2.4 \\
\hline Mango & 35.6 & 11.6 & 0.8 & 8.0 & 0.4 & 40.0 & 8.0 & 1.2 & 9.6 & 1.6 \\
\hline Pineapple & 19.2 & 6.8 & 0.8 & 4.8 & 1.6 & 2.8 & 6.8 & 1.6 & 7.2 & 2.8 \\
\hline Watermelon & 19.2 & 7.6 & 0.8 & 5.2 & 0.4 & 26.8 & 5.2 & 0.8 & 9.6 & 2.0 \\
\hline Average & 25.9 & 9.1 & 1.2 & 5.7 & 0.9 & 32.7 & 6.7 & 1.3 & 17.9 & 2.5 \\
\hline \multicolumn{11}{|l|}{ Major } \\
\hline \multicolumn{11}{|l|}{ Vegetables } \\
\hline Cabbage & 12.0 & 10.0 & 30.8 & 7.2 & 1.6 & 18.0 & 8.4 & 30.4 & 13.6 & 1.6 \\
\hline Pechay & 8.8 & 10.4 & 23.2 & 10.0 & 0.8 & 12.8 & 7.6 & 32.0 & 14.0 & 0.8 \\
\hline Eggplant & 9.2 & 15.6 & 25.6 & 5.2 & 1.2 & 13.2 & 10.0 & 29.6 & 9.2 & 1.2 \\
\hline Squash & 6.4 & 8.4 & 26.4 & 4.8 & 1.6 & 12.0 & 6.4 & 24.8 & 8.8 & 1.6 \\
\hline Carrot & 9.6 & 9.2 & 23.6 & 6.0 & 1.2 & 15.2 & 6.4 & 27.2 & 11.6 & 1.2 \\
\hline Tomato & 10.8 & 13.6 & 24.4 & 13.2 & 0.8 & 19.2 & 7.6 & 28.8 & 16.4 & 0.8 \\
\hline Onion & 9.2 & 10.4 & 22.8 & 8.4 & 1.2 & 14.4 & 8.4 & 24.8 & 17.6 & 1.2 \\
\hline Potato & 8.0 & 11.2 & 24.4 & 7.2 & 1.6 & 15.6 & 6.8 & 28.0 & 12.4 & 1.6 \\
\hline Bitter gourd & 9.2 & 7.6 & 25.6 & 6.8 & 1.6 & 12.8 & 5.2 & 28.0 & 10.4 & 1.6 \\
\hline String beans & 7.6 & 6.4 & 26.8 & 5.6 & 0.8 & 16.0 & 5.6 & 25.6 & 10.0 & 0.8 \\
\hline Average & 9.8 & 10.2 & 25.3 & 7.4 & 1.2 & 14.9 & 7.2 & 25.3 & 7.4 & 1.2 \\
\hline
\end{tabular}

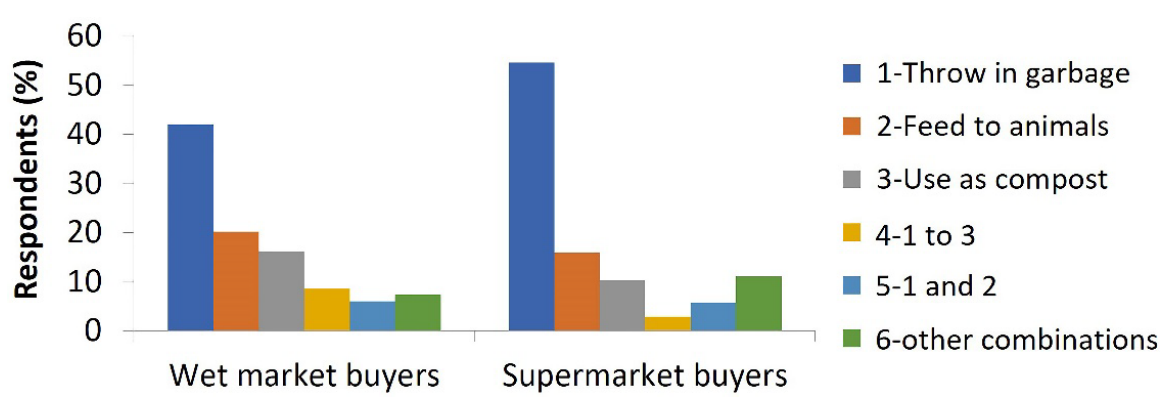

Figure 7. Ways of disposing wastes, by respondent group.

and vegetables as compost.

Consumer Efforts to Reduce Fruit and Vegetable Waste

Respondents were asked whether they made any effort to reduce the wastage of the fresh produce purchased by them. A high percentage replied "yes". The two most common methods of reducing waste of fresh produce, were through 
buying produce for immediate consumption and the immediate use of produce that was purchased (Table 7). When asked as to the other ways of minimizing wastes, the common answers were: a) regular monitoring of produce at home b) giving away to others the excess fruits and vegetables bought, and c) discarding damaged parts of the produce, to allow for consumption of sound portions of it.

Correlation between Quantities Bought, Levels of Waste and Sociodemographic Profile

A correlation analysis was performed to ascertain the relationship between the quantities of fruits and vegetables purchased with demographic characteristics and the quantities of fruits and vegetables wasted (Table 8 and Table 9). There

Table 7. Efforts to minimize fruit and vegetable waste at the consumer level.

\begin{tabular}{ccc}
\hline \multirow{2}{*}{ Method } & Wet Market Shoppers & \multicolumn{2}{c}{ Supermarket Shoppers } \\
\cline { 2 - 3 } & \multicolumn{2}{c}{ Percent Reporting $^{*}$} \\
\hline Buy enough for consumption & 43.2 & 28.8 \\
Consume/use immediately & 23.6 & 18.8 \\
Plan menu & 6.0 & 7.6 \\
Proper storage & 6.8 & 6.4 \\
Buy only good quality & 4.4 & 1.6 \\
Others & 4.4 & 5.2 \\
\hline
\end{tabular}

${ }^{*}$ Not all respondents gave answer and some respondents gave more than one answer.

Table 8. Correlations between the amount of fruits purchased and wasted, and selected demographic characteristics.

\begin{tabular}{|c|c|c|c|c|c|c|}
\hline & & Age & HH Size & HH Income & Qty Fruits & Fruit Waste \\
\hline \multirow{3}{*}{ Age } & Correlation Coefficient & 1.000 & $-0.103^{\star}$ & 0.022 & $0.103^{*}$ & $-0.092^{\star}$ \\
\hline & Sig. (2-tailed) & . & 0.026 & 0.643 & 0.022 & 0.043 \\
\hline & $\mathrm{N}$ & & 466 & 451 & 490 & 490 \\
\hline \multirow{3}{*}{ HH Size } & Correlation Coefficient & & 1.000 & $0.162^{* *}$ & $0.207^{\star *}$ & $0.107^{\star}$ \\
\hline & Sig. (2-tailed) & & . & 0.001 & 0.000 & 0.019 \\
\hline & $\mathrm{N}$ & & & 440 & 476 & 476 \\
\hline \multirow{3}{*}{ HH Income } & Correlation Coefficient & & & 1.000 & $0.124^{\star *}$ & 0.088 \\
\hline & Sig. (2-tailed) & & & 0. & 0.008 & 0.059 \\
\hline & $\mathrm{N}$ & & & & 461 & 461 \\
\hline \multirow{3}{*}{ Qty Fruits } & Correlation Coefficient & & & & 1.000 & $0.368^{\star *}$ \\
\hline & Sig. (2-tailed) & & & & 0. & 0.000 \\
\hline & $\mathrm{N}$ & & & & & 500 \\
\hline \multirow{3}{*}{ Fruit Waste } & Correlation Coefficient & & & & & 1.000 \\
\hline & Sig. (2-tailed) & & & & & . \\
\hline & $\mathrm{N}$ & & & & & 500 \\
\hline
\end{tabular}


Table 9. Correlations between the amount of vegetables bought and wasted, and selected demographic characteristics.

\begin{tabular}{|c|c|c|c|c|c|c|}
\hline & & Age & HH Size & HH Income & Qty Vege & Vege Waste \\
\hline \multirow{3}{*}{ Age } & Correlation Coefficient & 1.000 & $-0.103^{*}$ & 0.022 & -0.002 & -0.083 \\
\hline & Sig. (2-tailed) & . & 0.026 & 0.643 & 0.956 & 0.066 \\
\hline & $\mathrm{N}$ & & 466 & 451 & 490 & 490 \\
\hline \multirow{3}{*}{ HH Size } & Correlation Coefficient & & 1.000 & $0.162^{* *}$ & $0.260^{* *}$ & 0.072 \\
\hline & Sig. (2-tailed) & & 0. & 0.001 & 0.000 & 0.118 \\
\hline & $\mathrm{N}$ & & & 440 & 476 & 476 \\
\hline \multirow{3}{*}{ HH Income } & Correlation Coefficient & & & 1.000 & 0.066 & 0.026 \\
\hline & Sig. (2-tailed) & & & 0. & 0.158 & 0.577 \\
\hline & $\mathrm{N}$ & & & & 461 & 461 \\
\hline \multirow{3}{*}{ Qty Vege } & Correlation Coefficient & & & & 1.000 & $0.274^{* *}$ \\
\hline & Sig. (2-tailed) & & & & 0. & 0.000 \\
\hline & $\mathrm{N}$ & & & & & 500 \\
\hline \multirow{3}{*}{ Vege Waste } & Correlation Coefficient & & & & & 1.000 \\
\hline & Sig. (2-tailed) & & & & & . \\
\hline & $\mathrm{N}$ & & & & & 500 \\
\hline
\end{tabular}

${ }^{*}$ Correlation is significant at the 0.05 level (2-tailed); ${ }^{* *}$ Correlation is significant at the 0.01 level (2-tailed).

was a significant relationship between the quantities of fruits purchased, the age of the shopper, household size, and household income, while the quantities of vegetables purchased correlated only to household size. This means that older consumers who are usually more health conscious and those with bigger households buy comparably larger quantities of fruits and vegetables. Higher income households also buy larger quantities of fruits which are more expensive than vegetables.

On the other hand, the level of fruit waste showed a significant relationship to household size, meaning that larger households who also purchased larger quantities of fruits wasted more. This was not the case for vegetables given the small quantities purchased as compared to household size. Fruit waste also showed a negative correlation to age, meaning that younger consumers tend to waste more than older ones which corroborates the findings of Lipinski et al. (2013) [2].

Fruit and vegetable waste are significantly related to the quantities purchased. This implies that more wastes are incurred with higher quantities purchased. The level of fruit and vegetable waste also differed significantly based on the point of purchase (as shown in Table 4), affirming that the supermarket shoppers produced more waste than wet market shoppers.

\section{Conclusions and Recommendation}

Consumer level waste of fruits and vegetables was comparably low (around 3\% 4\%) for both wet market and supermarket buyers. This is likely due to the fact 
that small quantities (250 - 500 grams) of fresh produce were purchased by consumers in both markets. Almost all fruits and vegetables were sold in a loose format in fresh markets, hence the consumers have the flexibility in buying only the quantities needed. In the case of the supermarket, while fruits and vegetables are packaged, the quantity per pack is almost the same as that of the quantity purchased in the loose format by wet market buyers.

Consumer level fruit and vegetable waste was highly correlated to the quantities of fruits and vegetables purchased indicating that more wastes are incurred with larger purchases. The quantities of waste in both produce categories however differed by type of market shopper, affirming that consumers who shop in supermarkets waste more than those who shop in wet markets. On the other hand, consumer level waste of fruit was positively related to household size and household income, meaning that larger households and those with higher incomes wasted larger quantities of fruits, but fruit waste was negatively related to respondent's age, meaning that younger shoppers wasted more than older ones.

While consumer level waste of fruits and vegetable in urban households in the Philippines is relatively small, measures must still be instituted to minimize or further reduce the levels of these wastes in order to increase the consumption of these produce items. Consumer awareness must be raised, and consumers must be educated on the importance of minimizing wastes, through better handling and storage of the foods they purchase.

\section{Acknowledgements}

Funding support through a letter of agreement with the Food and Agriculture Organization of the United Nations-Regional Office for Asia the Pacific (FAO-RAP), and assistance of PHTRC staff, and, of Ms. Yasmin Fajardo are gratefully acknowledged.

\section{References}

[1] FAO (2011) Global Food Losses and Food Waste-Extent, Causes and Prevention. Rome.

[2] Parfitt, J., Barthel, M. and Macnaughton, S. (2010) Food Waste within Food Supply Chains: Quantification and Potential for Change to 2050 Review. Philosophical Transactions of the Royal Society B, 365, 3065-3081.

[3] Lipinski, B., Hanson, C., Lonax, J., Kitinoja, L., Waite, R. and Searchinger, T. (2013) Reducing Food Loss and Waste. Working Paper, Installment 2 of Creating a Sustainable Food Future. Washington DC: World Resources Institute. http://www.wri.org/our-work/project/world-resources-report/, Retrieved 10 Oct. 2014.

[4] WRAP [Waste and Resources Action Program] (2008) The Food We Waste. Banbury, UK.

[5] Peckan, G., Koksal, E., Kucukerdonmez, O. and Ozel, H. (2006) Household Food Wastage in Turkey. FAO, Rome, Italy.

[6] Muth, M.K., Kosa, K.M., Nielsen, S.J. and Karns, K.A. (2007) Exploratory Research on Estimation of Consumer Level Food Loss Conversion Factors. 
https://www.rti.org/sites/default/files/resources/13636370_0210449_food_loss_repo rt_7-07.pdf Retrieved 19 Oct. 2012.

[7] Chen, K., Shepherd, A. and da Silva, C. (2005) Changes in Food Retailing in Asia: Implications of Supermarket Procurement Practices for Farmers and Traditional Marketing System. Agric. Marketing and Finance Occasional Paper 8. FAO-UN, Rome, Italy, $35 \mathrm{p}$.

[8] Romo, G.D., Digal, L. and Reardon, T. (2009) The Transformation of Food Retail in the Philippines. Asian Journal of Agriculture and Development, 6, 51.

[9] UAP [University of Asia and the Pacific] (2011) The Changing Landscape of Philippine Supermarkets: Adapting to Emerging Consumer Trends. In: Agri Food Trade Service. An Overview of the Philippine Food Market. http://www.ats-sea.agr.gc.ca/ Retrieved 19 Oct. 2012.

[10] Anonymous (2012) Philippines: OMG! Eat-Your-Vegetables Campaign.

[11] Aban A.L., Concepcion, S.B. and Montiflor, M.O. (2009) Consumers' Perceptions on Food Safety of Vegetables in Davao City, Philippines. Banwa, 6, 13-30. 